\title{
INFLUÊNCIA DE ADUBAÇÕES E MANEJO DE ADUBO VERDE NOS ATRIBUTOS BIOLÓGICOS DE SOLO CULTIVADO COM ALFACE (LACTUCA SATIVA L.) EM SISTEMA DE CULTIVO ORGÂNICO
}

\author{
L.C. de Oliveira, J.R. Stangarlin, M. do C. Lana, D.N. Simon, A. Zimmermann
}

Universidade Estadual do Oeste do Paraná, Centro de Ciência Agrárias, Rua Pernambuco, 1777, CEP 85960000, Marechal Cândido Rondon, PR, Brasil. E-mail: llucioli@hotmail.com

\section{RESUMO}

\begin{abstract}
Devido à carência de informações sobre adubação orgânica para alface e uma avaliação quanto à sua influência nos atributos biológicos do ambiente, este trabalho objetivou estudar o efeito de diferentes sistemas de manejo da mucuna preta e o uso de adubação orgânica sólida sobre a diversidade e biomassa microbiana do solo. Os tratamentos consistiram do manejo da mucuna preta, incorporada ou não ao solo, e aplicação de esterco bovino, composto, adubo orgânico comercial e testemunha sem adubação. Os atributos foram avaliados nas seguintes épocas: momento do manejo da mucuna e aos 15, 55 e 105 dias após esse manejo. O manejo e os tratamentos com adubo orgânico sólido não influenciaram de forma significativa na biomassa microbiana e na população bacteriana do solo. Houve aumento na população de fungo coma incorporação da mucuna preta. A incorporação da mucuna preta e o tratamento com composto foram favoráveis para o incremento de fungos micorrízicos. O tratamento com composto, seguido da incorporação da mucuna preta, e o tratamento testemunha proporcionaram população superior de nematoides saprófitas, enquanto a incorporação da mucuna ao solo aumentou as populações de fitonematoides.
\end{abstract}

PALAVRAS-CHAVE: Agricultura orgânica, mucuna preta, biomassa microbiana.

ABSTRACT

INFLUENCE OF FERTILIZER, MANURE AND COMPOSTING ON THE BIOLOGICAL ATTRIBUTESOFSOIL CULTIVATEDWITHLETTUCE (LACTUCA SATIVA L.) IN AN ORGANIC CROP SYSTEM. Due to the lack of information on the application of commercial organic fertilizers versus manure or composting in the growing of lettuce and their influence on biological attributes of the environment, the present study was carried out to verify the effect of different management systems of velvet beans and the use of manure and solid organic composting on the diversity and microbial biomass of soil. The treatments consisted of the management of velvet beans, incorporated or not into the soil, and the application of bovine manure, composting, commercial organic fertilizer and a control treatment without fertilization. The soil attributes were evaluated at the following times: at the time of the velvet bean management, and at 15, 55 and 105 days after this process. The management and solid organic fertilizer treatments had no significant effect on the microbial biomass and bacterial population. For fungi, the incorporation of velvet bean was more efficient, allied to the use of commercial organic fertilizer. The incorporation of velvet bean and the treatment with composting were favorable for the grown of mycorrhizal fungi. Treatment with composting, followed by the incorporation of velvet beans, and the control treatment provided the higher population of saprophytic nematodes, while the incorporation of velvet bean into the soil increased the population of plant parasitic nematodes.

KEY WORDS: Organic agriculture, velvet bean, microbial biomass.

\section{INTRODUÇÃO}

Os modelos modernos de produção agrícola, caracterizados pela intensificação e padronização dos produtos e do processo produtivo, tornam os agroecossistemas cada vez mais dependentes de recursos externos. Altas produções devem-se em parte às práticas intensivas e ao uso de fertilizantes químicos sintéticos (AltierI, 2002).
Existem formas alternativas para uma produção mais sustentável, como a agricultura orgânica, que tem por princípio estabelecer sistemas de produção com base em tecnologias envolvendo a gerência e proteção dos recursos naturais sem o uso dos produtos químicos (BetTiol et al., 2002).

Omercado de produtos orgânicos vem crescendo no Brasil e no mundo. De acordo com EMATER (2007), no Paraná a área plantada em 2001 era de 500 ha e 
em 2005 passou para, aproximadamente, 1.200 ha. Neste contexto, o cultivo de hortaliças com adubos orgânicos tem aumentado e a cultura da alface (Lactuca sativa) representa a quarta hortaliça em importância no Brasil, sucedendo a batata, o tomate e a cebola (Mello et al., 2003).

De acordo com Khatounian (2001), o uso de adubos orgânicos aumenta a produção e mantém a fertilidade do solo. A matéria orgânica adicionada ao solo, de acordo com o grau de decomposição, pode ter efeito imediato ou efeito residual, por isso ganha importância sob o ponto de vista econômico e conservação das propriedades físicas, químicas e biológicas do solo. Associado aos adubos orgânicos, o produtor agroecológico pode dispor do uso de adubos verdes, como a mucuna preta (Mucuna aterrina), como uma ferramenta para incrementar a atividade microbiana no solo e a fertilidade (CASTRO et al., 2004).

A biomassa microbiana é composta por vários grupos de organismos, como vírus, bactérias, fungos, protozoários e actinomicetos, atuando no processo de decomposição da matéria orgânica, manutenção das condições físico-químicas, na ciclagem de nutrientes e no fluxo de energia (CARDOSO, 2004; D' ANDRÉA et al., 2002). Fungos e bactérias podem estabelecer relações simbióticas com plantas, aumentando assim a capacidade de resistência a estresses, como o déficit hídrico ou baixas concentrações de nutrientes, e ainda podem causar alterações físicas. Micorriza é uma associação simbiótica entre fungos benéficos e específicos do solo, e raízes de plantas, que resulta na melhoria na utilização e conservação de nutrientes e aumento da capacidade de absorção de alguns, principalmente o fósforo (MIRANDA; MiRANDA, 1997). Nematoides são organismos aquáticos que não podem ser vistos apenas como causadores de danos às culturas, pois existem nematoides de vida livre, que se alimentam de bactérias e fungos, assumindo papel importantíssimo na decomposição da matéria orgânica, por consequência, da produtividade das culturas (FreITAS et al., 2001).

Devido à carência de dados técnicos sobre adubação na alface em sistema orgânico de cultivo, o presente trabalho objetivou estudar práticas mais convenientes de manejo de adubos verdes e adubações orgânicas na atividade de bactérias, fungos e nematoides do solo.

\section{MATERIAL E MÉTODOS}

O experimento foi conduzido em região com solo tipo Latossolo Vermelho eutroférrico (LVef), com altitude de $420 \mathrm{~m}$ e precipitação média anual de $1.200 \mathrm{~mm}$.

A semeadura a lanço de mucuna preta $(M$. aterrima) ocorreu em novembro de 2007, em área de $140 \mathrm{~m}^{2}$. No mês maio de 2008 a área foi dividida ao meio para a realização do manejo da mucuna que se encontrava em floração. Foram feitos dois tipos de manejo: manejo I - incorporação do material vegetativo e levantamento de canteiros; manejo II - roçada da mucuna, sem incorporação. Quinze dias após este manejo, foi realizada a distribuição manual dos seguintes adubos orgânicos sólidos: esterco bovino curtido, obtido de uma propriedade orgânica; adubo orgânico comercial $(80 \%$ da sua composição com esterco de frango); e composto (esterco bovino $20 \%$, carvão vegetal $20 \%$ e restos vegetais de gramíneas $60 \%$ ).

A dose dos adubos foi definida de acordo com a necessidade de $\mathrm{N}$ pela cultura $\left(80 \mathrm{~kg} \mathrm{ha}^{-1}\right.$ ) (EMATER, 2007) e considerando-se o índice de eficiência de liberação de nutrientes no solo (Bissani et al., 2004). Foram utilizados 1,83 $\mathrm{kg} \mathrm{m}^{-2}$ de esterco bovino; $1,4 \mathrm{~kg} \mathrm{~m}^{-2}$ de adubo orgânico comercial; e $0,8 \mathrm{~kg} \mathrm{~m}^{-2}$ de composto. As Tabelas 1 e 2 apresentam os níveis de nutrientes encontrados nos adubos e no solo, respectivamente.

Tabela 1 - Concentração de nutrientes encontrados nos adubos orgânicos usados no experimento.

\begin{tabular}{|c|c|c|c|c|c|c|c|c|c|}
\hline Adubos & $\mathrm{N}$ & $\mathrm{P}$ & $\mathrm{K}$ & $\mathrm{Ca}$ & $\mathrm{Mg}$ & $\mathrm{Cu}$ & $\mathrm{Zn}$ & $\mathrm{Fe}$ & $\mathrm{Mn}$ \\
\hline & \multicolumn{5}{|c|}{ …................ $\left(\mathrm{g} \mathrm{kg}^{-1}\right) \ldots \ldots \ldots \ldots \ldots \ldots \ldots$} & \multicolumn{4}{|c|}{$\ldots \ldots \ldots \ldots \ldots\left(\mathrm{mg} \mathrm{kg}^{-1}\right) \ldots \ldots \ldots$} \\
\hline Esterco bovino & 13,1 & 2,60 & 21,6 & 26,0 & 3,5 & 196 & 279 & 2006 & 638 \\
\hline Adubo orgânico comercial & 11,4 & 16,60 & 37,8 & 120,9 & 1,2 & 145 & 336 & 713 & 740 \\
\hline Composto & 20,1 & 5,90 & 35,3 & 20,9 & 4,2 & 199 & 286 & 1990 & 677 \\
\hline
\end{tabular}

Tabela 2 - Características químicas do solo na camada 0-20 cm de profundidade, por ocasião do manejo da mucuna preta.

\begin{tabular}{ccccccccccc}
\hline $\mathrm{P}$ & $\mathrm{MO}$ & $\mathrm{Ph}$ & $\mathrm{H}+\mathrm{Al}$ & $\mathrm{K}^{+}$ & $\mathrm{Ca}^{3+}$ & $\mathrm{Mg}^{2+}$ & $\mathrm{SB}$ & $\mathrm{CTC}$ & $\mathrm{V}$ & $\mathrm{Al}$ \\
\hline $\mathrm{mg} \mathrm{dm}^{-3}$ & $\mathrm{~g} \mathrm{dm}^{-3}$ & $\mathrm{CaCl}_{2}$ & & $\ldots \ldots \ldots \ldots \ldots \ldots \ldots \ldots \mathrm{cmol}_{\mathrm{c}} \mathrm{dm}^{-3} \ldots \ldots \ldots \ldots \ldots \ldots$ & & $\ldots \ldots \ldots \ldots \ldots \ldots \ldots \ldots$ \\
17,04 & 25,97 & 5,55 & 3,52 & 1,96 & 6,29 & 2,26 & 10,51 & 14,03 & 74,91 & 0,00 \\
\hline
\end{tabular}


Quarenta dias após a aplicação dos adubos orgânicos sólidos, foi realizado o plantio da alface (cultivar -Vanda- tipo crespa), em espaçamento de 0,3 $\mathrm{m} \times 0,3$ $\mathrm{m}$, totalizando 21 plantas por parcela. Os canteiros de 1,2 $\mathrm{m}$ de largura por $10 \mathrm{~m}$ de comprimento foram divididos em quatro parcelas. A colheita foi realizada 50 dias após o plantio das mudas. Foram realizadas análises dos atributos biológicos do solo (biomassa microbiana, densidade populacional defungos, bactérias e nematoides) nas seguintes épocas: momento do manejo da mucuna, aos 15 dias (momento da distribuição dos adubos orgânicos sólidos), 55 dias (momento do plantio da cultura da alface) e 105 dias (na ocasião da colheita da alface).

Para estimativa da biomassa microbiana de carbono, foi utilizado o método de fumigação-extração (SALIMON, 2003) em amostras de 100 g, originárias de 10 subamostras, coletadas na profundidade de $0-5 \mathrm{~cm}$.

A densidade populacional de fungos e bactérias no solo foi estimada pelo método de diluição em placa (Menezes; Silva-Hanlin, 1997). Para tanto, foi amostrado o solo na profundidade de $0-15 \mathrm{~cm}$, nas quatro épocas já descritas. Para a determinação de fungos e bactérias foram utilizadas as diluições $10^{2}$ e $10^{3}$, respectivamente. Para fungos foi utilizado o meio de Martin e para bactérias o meio ágarnutritivo, com três réplicas para cada diluição. As placas foram incubadas à $23^{\circ} \mathrm{C}$ por $24 \mathrm{~h}$ (bactérias) e $72 \mathrm{~h}$ (fungos).

A densidade de fungos micorrízicos arbusculares e de nematoides foi avaliada pelo método de decantação e peneiramento úmido associado ao método flotação centrífuga em solução de sacarose (JENKINS, 1964). Utilizaram-se amostras de $100 \mathrm{~g}$ de solo na camada $0-20 \mathrm{~cm}$ de profundidade, obtidas nas quatro avaliações do experimento. Após a extração, a identificação dos nematoides e esporos de fungos micorrízicos foi realizada em câmaras de Peters (MAI; Lyon, 1982; SiQueIRA; FrANCO, 1988).

O delineamento experimental foi o de blocos ao acaso com cinco repetições, em esquema de parcelas subdivididas. Os tratamentos dispostos na parcela principal foram os dois tipos de manejos para o adubo verde (mucuna incorporada e não incorporada) e nas subparcelas os quatro tratamentos com adubos orgânicos sólidos (com esterco bovino, adubo orgânico comercial, composto e testemunha sem adubação). Os dados foram submetidos à análise de variância e as médias comparadas pelo teste de Tukey, com $5 \%$ de probabilidade. As análises foram feitas com o auxílio do software SISVAR (FERREIRA, 2003).

\section{RESULTADOS E DISCUSSÕES}

\section{Biomassa Microbiana}

$\mathrm{Na}$ avaliação inicial no momento do manejo da mucuna preta para a profundidade de $0-5 \mathrm{~cm}$ foi observada biomassa microbiana de 143,36 mg kg-1. Quinze dias após (na segunda avaliação), verificou-se biomassa microbiana de $167,32 \mathrm{mg} \mathrm{kg}^{-1}$ no manejo I e de $203,72 \mathrm{mg} \mathrm{kg}^{-1}$ no manejo II.

O manejo e os tratamentos com adubo orgânico sólido não influenciaram de forma significativa na biomassa microbiana (por isso os dados não foram apresentados). Para avaliação na época de plantio, valores numericamente superiores foram observados com o manejo I, e com tratamento composto. De acordo com FERREIRA et al. (2007), a mobilização do solo, por proporcionar a incorporação de resíduos orgânicos pode, em curto prazo, elevar a biomassa microbiana por disponibilizar substrato orgânico com a quebra dos agregados do solo, mas, em longo prazo, pode ter efeitos negativos, como a diminuição dos teores de matéria orgânica.

Na avaliação de colheita, valores numericamente superiores foram observados com a adubação com esterco bovino para o manejo I, e com adubação com composto no manejo II. Valores inferiores foram observados no tratamento testemunha para ambos os manejos. Dados concordantes foram verificados por SANTOS et al. (2004) e Melero et al. (2005), onde o sistema plantio direto, comparado com o convencional, proporcionou aumento na biomassa microbiana do solo

De acordo com D' ANDRÉA et al. (2002), os compostos orgânicos incrementam a biomassa microbiana, em comparação aos fertilizantes inorgânicos, porque ocorre aumento nas proporções de carbono e nitrogênio lábeis, estimulando diretamentea atividade da biomassa. Neste contexto, pode-se estabelecer maior diversidade de microrganismos decompositores com maior eficiência na utilização do substrato.

\section{Bactérias}

Para a população de bactérias na primeira época de avaliação (momento do manejo da mucuna) foi verificada uma média de 51,5 x $10^{2} \mathrm{UFC} \mathrm{g}^{-1}$ de solo. Na segunda avaliação (15 dias após o manejo da mucuna, e no momento da distribuição dos adubos orgânicos), para o manejo I foi verificada uma média de $97 \times 10^{2} \mathrm{UFC}^{-1}$ e para o manejo II foram 193,66 $x 10^{2} \mathrm{UFC} \mathrm{g}^{-1}$ de solo.

Os manejos utilizados com a mucuna preta não interferiram de forma significativa para as épocas de plantio e colheita da alface (dados não apresentados). Observaram-se valores inferiores com a não incorporação da mucuna, com exceção da adubação com composto na avaliação de colheita, possivelmente pela maior taxa de disponibilização de nutrientes.

MEISTER et al. (2006), avaliando população microbiana em sistema de cultivo convencional e ecológico, 
observaram pequenas variações de população de bactérias entre os sistemas, mas o solo com sistema ecológico apresentou maior contagem de bactérias. Os autores concluíram que as populações são maiores em solos cultivados com cobertura morta do que os cultivados com sistema convencional e isso também se aplica a adubações orgânicas.

Quando secomparam asépocas dentro do manejo I e manejo II observa-se que para os dois manejos houve decréscimo na população de bactérias naépoca da colheita da alface. Para LinDSTRÖM et al. (2004), esta redução pode estar associada à diminuição de nutrientes em função da colheita, à influência da cultura e a fatores de umidade do solo. Na época de plantio havia maior quantidade de material orgânico sobre solo, o qual pode ter contribuído para a manutenção da umidade do solo, o pH e a quantidade de fósforo disponível. Souto et al. (2008) obtiveram aumento na população de bactérias e fungos, com aumento da disponibilidade de resíduos orgânicos no solo.

\section{Fungos}

Para a primeira época de avaliação (momento do manejodamucuna) a densidadepopulacionaldefungos foi em média de 36,6 $\times 10^{2} \mathrm{UFC}^{-1}$ de solo. Na segunda avaliação (15 dias após o manejo, ou seja, no momento da distribuição dos adubos orgânicos sólidos), para o manejo I foi obtida uma média de $34,5 \times 10^{2} \mathrm{UFC} \mathrm{g}^{-1}$, e para o manejo II a média foi de $11,6 \times 10^{2} \mathrm{UFC} \mathrm{g}^{-1}$.

Na avaliação do plantio a população de fungos não foi afetada de forma significativa pelas adubações (Tabela 3). Porém, comparando as formas de manejo, os índices populacionais foram maiores para o manejo I, diferindo significativamente para o tratamento testemunha (sem adubação). Para a avaliação na época de colheita, observou-se diferença significativa entre os tratamentos para o manejo I, com número superior de colônia para a testemunha, e menor com o uso de esterco bovino. Para o manejo
II, a população não foi afetada de forma significativa pelas adubações.

O efeito do adubo verde incorporado ao solo foi observado para as duas épocas de avaliação, com elevação da densidade populacional no tratamento testemunha, que só expressa os efeitos do manejo da mucuna preta.

De acordo com Miranda et al. (1997), a presença de matéria orgânica e de material mineral pouco alterado nas camadas superficiais do solo favorece a maior aeração e disponibilidade de nutrientes, que favorece o aumento da população de bactérias e fungos. Na avaliação deste estudo, a incorporação da palhada no tratamento testemunha pode ter disponibilizado mais nutrientes aos fungos. Souto et al. (2008) verificaram aumento na população de fungos e bactérias, com aumento da umidade do solo, umidade esta favorecida pela maior disponibilidade de resíduos orgânicos decorrente do crescimento do estrato herbáceo na área, e ainda, aumentado pela maior oferta denutrientes. Estas alterações observadas podem ser decorrência da heterogeneidade temporal e espacial das comunidades microbianas no solo, o que dificulta o estudo da biodiversidade microbiana (CALBRIX et al., 2005).

\section{Fungos micorrízicos}

Na área estudada foram identificadas duas espécies de fungos micorrízicos arbusculares (FMA), Glomus macrocarpum e Scutellospora heterogama (Tabela 4). A população inicial desses fungos na primeira avaliação (momento do manejo da mucuna) foi de 6,40 indivíduos $100 \mathrm{gg}^{-1}$ de solo de $S$. heterogama e 9,20 indivíduos $100 \mathrm{~g}^{-1}$ de solo de G. macrocarpum. Quinze dias após o manejo da mucuna, para o manejo I foram observados 3,80 indivíduos $100 \mathrm{~g} \mathrm{~g}^{-1}$ de solo de $S$. heterogama e 7,20 indivíduos $100 \mathrm{~g}^{-1}$ de solo de G. macrocarpum. Para o manejo II foram verificados 1,20 indivíduos $100 \mathrm{~g}^{-1}$ de solo de S. heterogama e 9,60 indivíduos $100 \mathrm{~g}^{-1}$ de solo de G. macrocarpum.

Tabela 3 - Densidade populacional de fungos no solo em função do manejo da adubação verde com mucuna preta ${ }^{1}$ e da adubação orgânica sólida, nas épocas de plantio e colheita da cultura da alface.

\begin{tabular}{lcccc}
\hline \multirow{2}{*}{ Tratamentos $^{2}$} & \multicolumn{2}{c}{ Plantio } & \multicolumn{2}{c}{ Colheita } \\
\cline { 2 - 5 } & Manejo I & Manejo II & Manejo I & Manejo II \\
Esterco bovino & $-20,20 \mathrm{Aa}^{3}$ & $9,80 \mathrm{Aa}$ & $4,20 \mathrm{Ab}$ & $11,80 \mathrm{Aa}$ \\
Orgânico comercial & $15,00 \mathrm{Aa}$ & $12,40 \mathrm{Aa}$ & $35,80 \mathrm{Aab}$ & $32,00 \mathrm{Aa}$ \\
Composto & $23,40 \mathrm{Aa}$ & $4,80 \mathrm{Aa}$ & $13,20 \mathrm{Ab}$ & $15,80 \mathrm{Aa}$ \\
Testemunha & $39,40 \mathrm{Aa}$ & $6,20 \mathrm{Ba}$ & $63,20 \mathrm{Aa}$ & $28,40 \mathrm{Ba}$ \\
\hline CV $^{3}$ Tratamento (\%) & & & 43,56 & 51,44 \\
CV Manejo (\%) & & 31,19 & & \\
\hline
\end{tabular}

${ }^{1}$ Tipos de manejo da mucuna: I - incorporação do material vegetativo e levantamento de canteiros; II - roçada da mucuna, sem incorporação.

Os tratamentos (adubos) foram incorporados ao solo 40 dias antes do plantio da alface;

${ }^{2}$ Letras iguais minúsculas na coluna, para os tratamentos, e maiúscula na linha, para o manejo em cada época, não diferem entre si ao nível de $5 \%$ de probabilidade pelo teste de Tukey. 
Mesmo em curto espaço de tempo entre as avaliações, a população de fungos micorrízicos foi alterada pelo efeito da mucuna. Com a incorporação do adubo verde no manejo I e a não incorporação do adubo verdeno manejo II proporcionaram aumento na população de G. macrocarpum, para alguns tratamentos, comparado com a população inicial. As leguminosas estabelecem simbiose com fungos micorrízicos e têm grande capacidade de exploração do solo, o que é de fundamental importância, tanto para o equilíbrio biológico como para a reciclagem de nutrientes, proporcionando maior equilíbrio nutricional das plantas e maior resistência do sistema ao aparecimento de pragas e doenças (AMBROSANO et al., 2000).

Para S. heterogama, na avaliação no momento do plantio da alface, os tratamentos com adubos orgânicos sólidos não interferiram de forma significativa na população. No manejo II, no entanto, foi observado número superior com a adubação com composto, diferindo estatisticamente do manejo I. Para avaliação de colheita no manejo I, índices superiores foram observados com a adubação com composto e esterco bovino, diferindo estatisticamente do tratamento testemunha. No manejo II, a população de $S$. heterogama não diferiu em função da adubação orgânica. Menor população foi observada com a adubação com composto no manejo II em relação ao manejo I.

Nas avaliações da espécie G. macrocarpum, no momento do plantio da alface, os tratamentos com adubos orgânicos sólidos e manejos utilizados não interferiram de forma significativa. Para a avaliação de colheita, índices superiores foram observados no manejo I para a adubação com composto e esterco bovino, diferindo do tratamento testemunha. Maior população de G. macrocarpum foi observada no manejo I em relação ao manejo II com a adubação com composto.

De acordo com Andreola; Fernandes (2007), o sistema de plantio direto proporciona incremento tanto na colonização radicular quanto no número de propágulos de fungos micorrízicos, em relação ao convencional ou em sistemas em que o solo seja menos perturbado. No entanto, a micorrização pode ser inibida por excesso de fertilidade e os macronutrientes que exercem efeitos mais acentuados são o nitrogênio e fósforo. A disponibilidade de fósforo controla o grau de colonização micorrízica, ou seja, a adição de esterco ao solo por um lado beneficia a associação micorrízica estimulando o crescimento radicular do hospedeiro, mas por outro lado pode prejudicar o estabelecimento da micorriza pelo aumento na disponibilidade desse elemento no substrato (Souza et al., 2002). No presente trabalho as doses dos tratamentos foram iguais na quantidade de nitrogênio, mas o diferente grau de mineralização em conjunto com os nutrientes disponíveis no solo pode ter influenciado nos resultados.

Os levantamentos da diversidade de espécies de fungos micorrízicos arbusculares são importantes para o reconhecimento do potencial desse solo na formação de simbioses, mas além dessa identificação deespécies, seria adequado determinar a capacidade infectiva e o número mais provável de propágulos infectivos. Por isso, no presente trabalho é possível que o aumento na concentração de esporos tenha possibilitado aumentos no potencial de inóculo natural do solo, mas os tratamentos que proporcionaram maiores populações podem não ter contribuído para o processo de colonização.

Tabela 4 - População de fungos micorrízicos (número de esporângios $100 \mathrm{~g}^{-1}$ de solo) para adubação com adubos orgânicos sólidos e dois manejos de mucuna (I: roçada da mucuna, do material vegetativo e levantamento de canteiros; II: roçada da mucuna, sem incorporação), na época de plantio e colheita da cultura da alface.

\begin{tabular}{|c|c|c|c|c|}
\hline \multirow{3}{*}{$\begin{array}{l}\text { Tratamentos }^{1} \\
\text { Avaliação Plantio }\end{array}$} & \multicolumn{4}{|c|}{ Fungos Micorrízicos } \\
\hline & \multicolumn{2}{|c|}{ Scutellospora heterogama } & \multicolumn{2}{|c|}{ Glomus macrocarpum } \\
\hline & Manejo I & Manejo II & Manejo I & Manejo II \\
\hline Esterco bovino & $5,20 \mathrm{Aa}^{2}$ & $5,19 \mathrm{Aa}$ & $9,93 \mathrm{Aa}$ & $9,13 \mathrm{Aa}$ \\
\hline Orgânico Comercial & $7,46 \mathrm{Aa}$ & 4,53 Aa & $8,26 \mathrm{Aa}$ & $6,99 \mathrm{Aa}$ \\
\hline Composto & $3,66 \mathrm{Ba}$ & 7,73 Aa & 7,60 Aa & $10,60 \mathrm{Aa}$ \\
\hline Testemunha & $6,26 \mathrm{Aa}$ & $4,33 \mathrm{Aa}$ & 7,46 Aa & $10,73 \mathrm{Aa}$ \\
\hline $\mathrm{CV}^{3}$ Tratamento $(\%)$ & \multicolumn{2}{|c|}{20,77} & \multicolumn{2}{|c|}{28,00} \\
\hline CV Manejo (\%) & \multicolumn{2}{|c|}{42,88} & \multicolumn{2}{|c|}{38,30} \\
\hline \multicolumn{5}{|l|}{ Avaliação Colheita } \\
\hline Esterco bovino & $8,00 \mathrm{Aa}$ & $4,00 \mathrm{Aa}$ & $12,00 \mathrm{Aa}$ & $7,80 \mathrm{Aa}$ \\
\hline Orgânico Comercial & $4,20 \mathrm{Aab}$ & $4,00 \mathrm{Aa}$ & $7,60 \mathrm{Aab}$ & $10,40 \mathrm{Aa}$ \\
\hline Composto & $8,00 \mathrm{Aa}$ & $3,60 \mathrm{Ba}$ & $12,00 \mathrm{Aa}$ & $7,80 \mathrm{Ba}$ \\
\hline Testemunha & $2,60 \mathrm{Ab}$ & $2,80 \mathrm{Aa}$ & $5,20 \mathrm{Ab}$ & $7,60 \mathrm{Aa}$ \\
\hline $\mathrm{CV}^{3}$ Tratamento (\%) & \multirow{2}{*}{\multicolumn{2}{|c|}{31,57}} & \multicolumn{2}{|c|}{26,69} \\
\hline CV Manejo (\%) & & & & \\
\hline
\end{tabular}

${ }^{\mathrm{T}}$ Os tratamentos (adubos) foram incorporados ao solo 40 dias antes do plantio da alface.

${ }^{2}$ Letras iguais minúsculas na coluna, para os tratamentos, e maiúscula na linha, para o manejo, não diferem entre si ao nível de $5 \%$ de probabilidade pelo teste de Tukey. 


\section{Nematoides}

Nas avaliações denematoides foram identificados alguns saprófitas e dois gêneros fitopatogênicos, Aphelenchoides e Helicotylenchus (Tabela 5). A população inicial no momento do manejo da mucuna foi em média de 17,6 nematoides saprófitas $100 \mathrm{~g}^{-1}$ de solo e 25,60 indivíduos do gênero Helicotylenchus $100 \mathrm{~g}^{-1}$ de solo.

Na segunda avaliação, 15 dias após o manejo da mucuna, para o manejo I foram observados 13,6 nematoides saprófitas $100 \mathrm{~g}^{-1}$ de solo e 12 indivíduos do gênero Helicotylenchus $100 \mathrm{~g}^{-1}$ de solo. Para o manejo II foram verificados 10,4 nematoides saprófitas $100 \mathrm{~g}^{-1}$ de solo e 15,8 indivíduos do gênero Helicotylenchus $100 \mathrm{~g}^{-1}$ de solo. O gênero Aphelenchoides só foi verificado a partir da terceira avaliação, no momento do plantio da cultura da alface. Os manejos utilizados afetaram os nematoides no solo, reduzindo, de forma geral, as populações.

$\mathrm{Na}$ avaliação de plantio, os manejos e os tratamentos com adubo orgânico sólido influenciaram de forma significativa na população de nematoides saprófitas. No manejo I, para a adubação com composto e tratamento testemunha, foram observados maiores índices populacionais. No manejo II, populações mais elevadas foram verificadas com adubação com adubo orgânico comercial, diferindo da adubação com composto e tratamento testemunha. $\mathrm{Na}$ avaliação de colheita, os manejos da mucuna e os tratamentos não influenciaram deforma significativa na população de nematoides. Comparando as duas épocas de amostragem verificou-se redução para todos os tratamentos na avaliação de colheita no manejo I. Pujol et al. (2004), estudando a dinâmica de nematoides em sistema de cultivo orgânico, verificaram que a população desses organismos diferiu significativamente entre os tratamentos para as culturas de batata, soja e milho, porém, isto não ocorreu na cultura do feijão, demonstrando que a cultura pode interferir nas populações de nematoides.

Nacontagem da populaçãodogênero Aphelenchoides os manejos e as adubações não influenciaram de forma significativa na avaliação do plantio. Na avaliação de colheita os manejos da mucuna e as adubações influenciaram significativamente. Para a adubação com composto, a incorporação da mucuna proporcionou aumentos significativos quando comparado com manejo II, não incorporado, diferindo do tratamento com adubo orgânico comercial e tratamento testemunha. No manejo II, as adubações não influenciaram significativamente a população de Aphelenchoides sp.

$\mathrm{Na}$ contagem da população do gênero Helicotylenchus, o manejo da mucuna influenciou de forma significativa para a adubação com composto, nas duasépocas avaliadas, comíndices populacionais superiores no manejo II na avaliação de plantio, e com índices populacionais superiores para o manejo I na avaliação de colheita da alface. No plantio, os tratamentos não influenciaram de forma significativa. Na colheita do manejo I, populações maiores foram verificadas com a adubação com composto comparado a testemunha, não havendo influencia dos adubos no manejo II.

Tabela 5 - População de nematoides saprófitas e fitopatogênicos (indivíduos $100 \mathrm{~g}^{-1}$ de solo) para adubação com adubos orgânicos sólidos e dois manejos de mucuna (I: roçada da mucuna, do material vegetativo e levantamento de canteiros; II: roçada da mucuna, sem incorporação), na época de plantio e colheita da cultura da alface.

\begin{tabular}{|c|c|c|c|c|c|c|}
\hline \multicolumn{7}{|c|}{ População de nematoides (indivíduos $100 \mathrm{~g}^{-1}$ solo) } \\
\hline \multirow{2}{*}{ Tratamentos $^{1}$} & \multirow{2}{*}{\multicolumn{2}{|c|}{ Nematoides saprófitas }} & \multicolumn{4}{|c|}{ Nematoides fitopatogênicos } \\
\hline & & & \multicolumn{2}{|c|}{ Aphelenchoides sp. } & \multicolumn{2}{|c|}{ Helicotylenchus sp. } \\
\hline Avaliação Plantio & Manejo I & Manejo II & Manejo I & Manejo II & Manejo I & Manejo II \\
\hline Esterco bovino & $9,20 \mathrm{Ab}^{2}$ & $5,80 \mathrm{Aab}$ & $0,86 \mathrm{Aa}$ & $2,40 \mathrm{Aa}$ & $9,00 \mathrm{Aa}$ & $7,60 \mathrm{Aa}$ \\
\hline Orgânico comercial & $9,40 \mathrm{Ab}$ & $16,60 \mathrm{Aa}$ & $1,86 \mathrm{Aa}$ & $0,53 \mathrm{Aa}$ & $8,46 \mathrm{Aa}$ & $6,46 \mathrm{Aa}$ \\
\hline Composto & $20,80 \mathrm{Aa}$ & $0,70 \mathrm{Bb}$ & $1,86 \mathrm{Aa}$ & $2,60 \mathrm{Aa}$ & $6,73 \mathrm{Aa}$ & $22,46 \mathrm{Aa}$ \\
\hline Testemunha & $24,00 \mathrm{Aa}$ & $0,70 \mathrm{Bb}$ & $3,00 \mathrm{Aa}$ & $0,80 \mathrm{Aa}$ & $7,40 \mathrm{Aa}$ & $14,46 \mathrm{Aa}$ \\
\hline $\mathrm{CV}^{3}$ Tratamento (\%) & \multicolumn{2}{|c|}{56,64} & \multicolumn{2}{|c|}{43,36} & \multicolumn{2}{|c|}{48,34} \\
\hline CV Manejo (\%) & \multicolumn{2}{|c|}{52,19} & \multicolumn{2}{|c|}{49,38} & \multicolumn{2}{|c|}{49,17} \\
\hline \multicolumn{7}{|l|}{ Avaliação Colheita } \\
\hline Esterco bovino & $7,80 \mathrm{Aa}$ & $10,00 \mathrm{Aa}$ & $5,60 \mathrm{Aab}$ & $5,60 \mathrm{Aa}$ & $27,60 \mathrm{Aab}$ & $21,60 \mathrm{Aa}$ \\
\hline Orgânico comercial & $7,40 \mathrm{Aa}$ & $5,60 \mathrm{Aa}$ & $4,20 \mathrm{Ab}$ & $5,20 \mathrm{Aa}$ & $29,80 \mathrm{Aab}$ & $21,80 \mathrm{Aa}$ \\
\hline Composto & $10,60 \mathrm{Aa}$ & $8,40 \mathrm{Aa}$ & $7,60 \mathrm{Aa}$ & $4,00 \mathrm{Ba}$ & $56,40 \mathrm{Aa}$ & $24,40 \mathrm{Ba}$ \\
\hline Testemunha & $5,40 \mathrm{Aa}$ & $3,80 \mathrm{Aa}$ & $4,20 \mathrm{Ab}$ & $3,80 \mathrm{Aa}$ & $18,60 \mathrm{Ab}$ & $21,60 \mathrm{Aa}$ \\
\hline $\mathrm{CV}^{3}$ Tratamento (\%) & \multicolumn{2}{|c|}{40,27} & \multicolumn{2}{|c|}{25,96} & \multicolumn{2}{|c|}{29,66} \\
\hline CV Manejo (\%) & \multicolumn{2}{|c|}{23,79} & \multicolumn{2}{|c|}{13,73} & \multicolumn{2}{|c|}{27,44} \\
\hline
\end{tabular}

${ }^{1}$ Os tratamentos (adubos) foram incorporados ao solo 40 dias antes do plantio da alface.

${ }^{2}$ Letras iguais minúsculas na coluna, para os tratamentos, e maiúscula na linha, para o manejo, não diferem entre si ao nível de 5\% de probabilidade pelo teste de Tukey.

${ }^{3} \mathrm{CV}$ : coeficiente de variação.

Arq. Inst. Biol., São Paulo, v.79, n.4, p.557-565, out./dez., 2012 
Neste trabalho, para o gênero Helicotylenchus, verificou-se uma redução em relação à primeira avaliação e a época de plantio. Uma provável explicação para a redução da população de nematoides no solo pela adição de matéria orgânica é a liberação de compostos tóxicos durante a sua decomposição, o favorecimento de populações de inimigos naturais e o aumento na presença e atividade de microorganismos benéficos do solo (PereIRA, 2006). De acordo com Alves et al. (2007), uma hipótese a ser estudada é que com a adição de adubos orgânicos ao solo, as plantas cultivadas se desenvolvam mais vigorosamente, com sistemas radiculares maiores e assim toleram uma carga maior de nematoides.

BRINGEL; SILVA (2000), estudando efeitos antagônicos de algumas espécies de plantas a Helicotylenchus multicinctus, observaram redução significativa na população deste nematoide com o uso de Crotalaria spetabilis, C. juncea, Mucuna aterrina, M. nivea, arroz, milho e caupi, concordando com os resultados deste trabalho, onde com o uso de mucuna preta no tratamento testemunha foi verificada redução da população de nematóides quando comparada com a população inicial.

Deacordo com RITZINGER; FANCELLI (2006), estudos envolvendo a incorporação de materiais vegetais no controle de nematoides têm sido realizados com sucesso, mas essa redução depende do tipo e da quantidade de material vegetal a ser incorporado. Para promover o manejo dos fitonematoides é necessário conhecer a relação $\mathrm{C} / \mathrm{N}$ e a produção de massa fresca e seca da espécie, mudanças no $\mathrm{pH}$ do solo decorrentes do uso dessas espécies como cobertura, bem como o teor de matéria orgânica.

A população denematoides fitopatogênicos muitas vezes tem sido correlacionada com a atividade de fungos e bactérias presentes em resíduos orgânicos adicionados ao solo (Asmus et al., 2002). No presente trabalho foi verificada a diminuição na população de fungos com o manejo I com exceção do tratamento comadubo orgânico comercial. Quando relacionado com a população de nematoide na mesma época de avaliação, verificou-se aumento na população dos nematoides fitoparasitas e diminuição dos saprófitas para o manejo I da mucuna.

Aos 60 dias após o plantio das hortaliças, (MORAES et al., 2006) observou-se, nas áreas incorporadas com crotalária, menor número de Helicotylenchus dihystera nas parcelas cultivadas com repolho, enquanto nas áreas cultivadas com alface americana a densidade populacional foi igual para todas as parcelas. No plantio em campo, de Crotalaria juncea e mucunapreta seguida pelo cultivo de Arachis hypogaea L., (Moura et al., 1997) não observaram diferenças no nível populacional de Helicotylenchus dihystera, demonstrando que o uso de adubação verde como tática de controle de fitonematoides pode ser viável para alguns patossistemas em cultivo orgânico, por isso deve ser integrado a alternativas de manejo como o uso de variedades resistentes, solarização e aração seguida de irrigação do solo, principalmente no cultivo orgânico, demonstrando a necessidade de avaliação no tempo e dosagens

\section{CONCLUSÃO}

O uso de mucuna preta, sem revolvimento, como cobertura do solo demonstra grande potencial para a cultura da alface, este manejo proporciona redução de mão-de-obra eredução decustos de produção. Quanto ao uso de adubos orgânicos sólidos, o tratamento com esterco bovino e composto mesmo sendo inferiores em relação ao tratamento com adubo orgânico comercial essa diferença não foi estatística para algumas características avaliadas, demonstrando que com o uso de adubos existentes na propriedade é possível alcançar resultados produtivos satisfatórios.

\section{REFERÊNCIAS}

ALTIERI, M. Agroecologia: bases científicas para uma agricultura sustentável. Guaíba: Agropecuária, 2002. $592 \mathrm{p}$.

ALVES, F.R.; FREITAS, L.G.; MARTINELLI, P.R.P.; MEIRA, R.M.S.A., FERRAZ, S., DEMUNER, A.J.; BORGES, E.E. de L.; JESUS JÚNIOR, W.C. Efeitos de diferentes níveis de matéria orgânica no solo e de inóculo sobre a interação planta-Meloidogyne spp. e a produção massal de Pasteuria penetrans. Summa Phytopathologica, v.33, n.4, p.397-401, 2007.

AMBROSANO, E.J.; MURAOKA, T.; AMBROSANO, G.M.B.; TRIVELIN, P.C.O; WUTKE, E.B.; TAMISO, L.G. $O$ papel das leguminosas para adubação verde em sistemas orgânicos. In: Curso regional de agricultura orgânica/ adubação verde para agricultura orgânica. Piracicaba-SP, p.17-76, 2000.

ANDREOLA, F.; FERNANDES, S.A.P.A Microbiota do solo na agricultura Orgânica e no Manejo das Culturas. In: SILVEIRA, A.P.D. da.; FREITAS, S. dos S. (Ed.). Microbiota do solo e qualidade ambiental. Campinas: Instituto Agronômico, 2007. Cap. 2. p.21-39.

ASMUS, G.L.; INOWE, T.S.; ANDRADE, P.J.M. Efeito da cama de frangos de corte sobre a reprodução de Meloidogyne javanica e o crescimento de plantas de tomateiro. Nematologia Brasileira, v.26, n.1, p.21-25, 2002.

BETTIOL, W.; GHINI, R.; GALVÃO, J.A.H.; LIGO, M.A.V.; MINEIRO, J.L. de C. Soil organisms in organic and conventional cropping systems. Scientia Agricola, v.59, n.3, p.565-572, 2002. 
BISSANI, C. A.; GIANELLO, C.; TEDESCO, J. M.; CAMARGO, F. A. de OLIVEIRA. Fertilidade dos solos e manejo da adubação de culturas. Porto Alegre: Genesis, 2004. 328p.

BRINGEL, J.M.M; SILVA, G.S. Efeito antagônico de algumas espécies de plantas a Helicotylenchus multicinctus. Nematologia Brasileira, v.24, n.2, p.179-181, 2000.

CALBRIX, R.; LAVAL, K.; BARRAY, S. Analysis of the potential functional diversity of the bacterial community in soil: a reproducible procedure using sole-carbonsource utilization profiles. European Journal of Soil Biology, v.41, n.1/2, p.11-20, 2005.

CARDOSO, M. O. Método para quantificação da biomassa microbiana do solo. Agropecuária Técnica, v.25, n.1, p.1-12, 2004.

CASTRO, C.M; ALVES, B.J.R.; ALMEIDA, D.L.; RIBEIRO, R.L.D. Adubação verde como fonte de nitrogênio para a cultura da berinjela em sistema orgânico. Pesquisa Agropecuária Brasileira, v.39, n.8, p.779-785, 2004.

D'ANDRÉA, A.F.; SILVA, M.L.N.; CURI, N.; SIQUEIRA, M.A.C. Atributos biológicos indicadores da qualidade do solo em sistemas de manejo na região do Cerrado no sul do Estado de Goiás. Revista Brasileira de Ciência do Solo, v.26, p.913-923, 2002.

EMATER - INSTITUTO PARANAENSE DE ASSISTÊNCIA TÉCNICA E EXTENSÃO RURAL. Manual de olericultura orgânica/Emater SEAB. Curitiba: Emater, 2007. 128p. (Informação técnica, 109).

FERREIRA, D.F. SISVAR - Sistemas de Analises Estatísticas. Lavras: UFLA, 2003.

FERREIRA, E.A.B.; RESCK, D.V.S.; GOMES, A.C.; RAMOS, M.L.G. Dinâmica do carbono da biomassa microbiana em cinco épocas do ano em diferentes sistemas de manejo do solo no cerrado. Revista Brasileira da Ciência do Solo, v.31, p.1625-1635, 2007.

FREITAS, L.G.; OLIVEIRA, R.'D.A.; FERRAZ, S. Introdução à nematologia. Viçosa: UFV, 2001. 84p.

JENKINS, W.R. A rapid centrifugal-flotation technique for separating nematodes from soil. Plant Disease Reporter, v.48, p.692, 1964.

KHATOUNIAN, C. A. A Reconstituição ecológica da agricultura. Botucatu: Agroecológica, 2001. 348p.

LINDSTRÖM, E.S.; VREDE, K.; LESKINEN, E. Response of a member of the Verrucomicrobia, among the dominating bacteria in a hypolimnion, to increased phosphorus availability. Journal of Plankton Research, v.26, n.2, p.241-246, 2004.

MAI W.F.; LYON H.H. Pictorial key to genera of plant-parasitic nematodes. 4.ed. 1982. 220p.
MEISTER, J.V.; WISNIEWSKI, C.; SOUZA, R.M. Ação e comparação da população microbiana em sistema de cultivo convencional e ecológico em propriedades familiares na região centro-sul do Paraná. Revista Brasileira de Agroecologia, v.1, n.1, 2006.

MELERO, S.; PORRAS, J.C.R.; HERENCIA, J.F.; MADEJON, E. Chemical and biochemical properties in a silty loam soil under conventional and organic management. Soil \& Tillage Research, v.90, p.162-170, 2005.

MELLO, J.C.; DIETRICH. R.; MEINCRT, E.M.; TEXEIRA, E.; AMANTE, E. Efeitos do cultivo orgânico e convencional sobre a vida-de-prateleira de alface americana. Ciência Tecnológica de Alimentos, v.23, n.3, p.418-426, 2003.

MENEZES M.; SILVA-HANLIN, D.M.W. Guia prático para fungos fitopatogênicos. Recife: UFRPE, Imprensa Universitária da UFRPE, 1997. 106p.

MIRANDA. J.C.C. de; MIRANDA L.N. de. Micorrizas arbuscular. In: VARGAS, M.A.T.; HUNGRIA, M. (Ed.). Biología dos solos dos Cerrados. Planaltina: EMBRAPA-CPAC, 1997. Cap.2. 69-123.

MIRANDA, C.S.S.; FERREIRA, M.G.V.X.; MENEZES, M. Atividade biológica de solos com A Chernozêmico na Zona da Mata Norte de Pernambuco. In: CONGRESSO BRASILEIRO DE CIÊNCIAS DO SOLO. 26., 1997.Rio de Janeiro. Anais. Rio de Janeiro, Sociedade Brasileira de Ciência do Solo, 1997. p.1-4.

MORAES, S.R.G.; CAMPOS, V.P.; POZZA, E.A.; FONTANETTI, A.; CARVALHO, G.J.; MAXIMINIANO, C. Influência de leguminosas no controle de fitonematóides em cultivo orgânico de alface americana e repolho. Fitopatologia Brasileira, v.31, p.188-191, 2006.

MOURA, R.M.; MOURA, A.M.; MACEDO, M.E.A.; SILVA, E.G. Influência de três diferentes combinações de culturas sobre populações de nematóides associados à cana-de-açúcar. Nematologia Brasileira, v.21, p.75-83, 1997.

PEREIRA, A.M. Identificação e manejo de nematóides da bananeira no leste do estado do Paraná. 2006. 110f. Dissertação (Mestrado em Agronomia) - Universidade Federal do Paraná, Curitiba, 2006.

PUJOL, S.B.; QUADROS, V.J. de; ANTONIOLLI, Z.I.; DENEGA, G.L.; CASALI, C.A.; WEBER, M.A. Nematóide em sistema de cultivo orgânico de batata, soja, feijão e milho. In: REUNIÃO BRASILEIRA DE FERTILIDADE DO SOLO E NUTRIÇÃO DE PLANTAS, 26.; REUNIÃO BRASILEIRA SOBRE MICORRIZAS, 10.; SIMPÓSIO BRASILEIRO DE MICROBIOLOGIA DO SOLO, 8.; REUNIÃO BRASILEIRA DE BIOLOGIA DO SOLO, 5. 2004, Lages. Avaliação das conquistas: bases para estratégias futuras. Anais. Lages: UDESC: SBCS, 2004. CD-ROM. 
RITZINGER, C.H.S.; FANCELLI, M. Manejo integrado de nematóides na cultura da bananeira. Revista Brasileira de Fruticultura, v.28, n.2, p.331-338, 2006.

SALIMON, C. I. Respiração do solo sob florestas e pastagens na Amazônia Sul - Ocidental, Acre. Piracicaba, 2003. 97f. Tese (Doutorado em Ciência) - Centro de Energia Nuclear na Agricultura, Universidade de São Paulo, Piracicaba, 2003.

SANTOS, V.B. dos; CASTILHOS, D.D.; CASTILHOS, R.M.V.; PAULETTO, E.A.; GOMES, A. da S. ; SILVA, D.G. da Biomassa, atividade microbiana e teores de carbono e nitrogênio totais de um planossolo sob diferentes sistemas de manejo. Revista Brasileira Agrociência, v.10, n.3, p.33-338, 2004.

SIQUEIRA, J.O; FRANCO, A.A. Biotecnologia do solo: fundamentos e perspectiva. Brasília: MEC, ABEAS; Lavras: ESAL, FAEPE, 1988. 236p.
SOUTO, P.C.; SOUTO, J.S.; MIRANDA, J.. P de.; SANTOS, R. V. dos ; ALLYSON ALVES, R. Comunidade microbiana e mesofauna edáficas em solo sob caatinga no semi-árido da Paraíba. Revista Brasileira Ciência Solo, v. 32, p.151-160, 2008.

SOUZA, P.V.D. de.; SCHMITZ, J.A.K.; FREITAS, R.S. de F.; CARNIEL, E.; ROSILAINE CARRENHO, R. Identificação e quantificação de fungos micorrízicos arbusculares autóctones em municípios produtores de citros no Rio Grande do Sul. Pesquisa Agropecuária Brasileira, v.37, n.4, p.553-558, 2002.

Recebido em 23/2/11

Aceito em 15/10/12 